\title{
POR QUE ME AFETA?
}

\section{Giovana Aparecida Zimermann}

Pós-doutoranda na Universidade Federal do Rio de Janeiro (UFRJ), junto ao Instituto de Pesquisa e Planejamento Urbano Regional (IPPUR). Doutora em Literatura (PPGL) pela Universidade Federal do Estado de Santa Catarina UFSC (2015). Email: giovana_zimermann@ hotmail.com

\begin{abstract}
Resumo
O presente artigo aborda reflexões sobre minha atuação política e social, no campo da arte. Entre os exemplos estão a mostra O Lugar do Outro, realizada no Museu de Arte de Santa Catarina, como parte de um evento que lembrou os 20 anos do pensador francês Michel Foucault, em 2004. Um projeto de Arte Relacional, realizado no Presídio Feminino de Florianópolis, entre 2004 e 2005, intitulado Escreva a frase que te liberta, que iniciou colhendo depoimentos das mulheres em reclusão e finalizou com uma exposição de fotos no Museu da Imagem e do Som, em Florianópolis, e com um fórum para discutir o investimento na reinserção das mulheres no mercado de trabalho. No mesmo período fui afetada pelo depoimento de outra jovem mulher sobre um estupro sofrido. A afecção nos leva para uma potência maior de ser e agir no mundo. Com o passar do tempo, escrevi um roteiro ficcional de um curtametragem intitulado Da Janela, 2009. O audiovisual revela-se como dispositivo do discurso sobre a violência de gênero: por ser exibido em espaço para debates, o filme motivou o surgimento de outros dois curtas, relacionados com os três tempos mencionados por Jacques Lacan: instante de ver (Da Janela), tempo para compreender (branCURA), e momento de concluir (A Cor da Liberdade) ainda em processo.
\end{abstract}

\section{Palavras-chave}

Arte. Gênero. Liberdade. Sistema Prisional. Violência.

\section{WHY AFFECTS ME?}

\begin{abstract}
This article discusses reflections on my political and social activities in the field of Arts. For example includes the exhibition The Other Place, held at the Santa Catarina Art Museum as part of an event that recalled the 20 years of the French thinker Michel Foucault, in 2004. A Relational Art project, conducted by Women in Prison Florianópolis, between 2004 and 2005, entitled Type the phrase that sets you free, which started collecting testimonies of women in reclusion and ended with a photo exhibition at the Museum of Image and Sound in Florianópolis, and a forum to discuss investment in reintegration of women in the labor market. In the same period I was affected by another young woman's testimony about a suffering rape. This condition leads to greater power of being and acting in the world. I wrote a fictional script for a short film titled Window, 2009. The audiovisual is revealed as speech device on gender violence: to be displayed in space for debates, the film led to the emergence of two short films, related to the three times mentioned by Jacques Lacan: time to see (Window), time to understand (Whiteness), and time to complete (Freedom of color), still in process.
\end{abstract}

Keywords

Art. Genre. Freedom. Prison system. Violence. 


\section{INTRODUÇÃO}

Há algum tempo, meu alvo vem sendo as políticas corporais que dão ênfase ao corpo, sua fragilidade e vulnerabilidade física: a dor, o medo, a morte. Em 2004, realizei uma mostra de fotografia intitulada $O$ lugar do outro, uma abordagem sobre o Sistema Prisional. Nela citei a frase de Marianne Moore, para sinalizar os contrários: inocência/culpa: "O que é a nossa inocência, qual é a nossa culpa? Todos estão nus, ninguém está seguro, e onde está a coragem?". A frase era um questionamento quanto a minha própria atuação política e social.

No ano seguinte, Escreva a frase que te liberta foi um projeto de Arte Relacional que realizei dentro do Presídio Feminino de Florianópolis; eu já escrevia o roteiro do Da Janela (2009), meu primeiro curta-metragem, iniciado em 2003 e finalizado em 2009. Em virtude do assunto abordado (violência contra a mulher), Da Janela foi exibido sempre em espaço para debates, agregando artistas, psicanalistas, enfermeiros e assistentes sociais.

Os debates motivaram a criação de outros dois curtas, com o intuito de fechar o ciclo aberto pelo Da Janela. Do ponto de vista das cores, trata-se de uma referência à trilogia Trois Couleurs: Bleu/Blanc/Rouge, de Krzysztof Kieślowski (1993-1994). No Da Janela, o vermelho remete à sensualidade e à violência; em branCURA, o branco remete à limpeza obsessiva, mas também à lacuna deixada pelo trauma; e, no último, A Cor da Liberdade (em processo), será a vez do azul, como transcendência.

O enfoque psicanalítico da trilogia está relacionado com os três tempos mencionados por Jacques Lacan, quando se refere ao: instante de ver (Da Janela), tempo para compreender (branCURA), e momento de concluir (A Cor da Liberdade).

\section{O LUGAR DO OUTRO, 2004}

O lugar do outro fez parte de uma coletiva intitulada As palavras e as coisas, em um evento homenageando os 20 anos da morte de Michael Foucault. Nela abordei a temática do sistema prisional, utilizando uma frase do pensador francês, que resumia o sentimento que eu havia experimentado ao visitar o Centro Educacional São Lucas, a extinta instituição para menores infratores da região metropolitana de Florianópolis, que mais se assemelhava a uma casa 
de detenção, conforme fotografias da série que leva o nome da exposição (Figura1). Alerta Foucault:

A animalidade escapou à domesticação pelos valores e pelos símbolos humanos; e se ela agora fascina o homem com sua desordem, seu furor, sua riqueza de monstruosas impossibilidades, é ela quem desvenda a raiva obscura, a loucura estéril que reside no coração dos homens (FOUCAULT, 2004, p. 18).

Figura 1 - Fotografias 1 e 2 da série $O$ lugar do outro, 2004

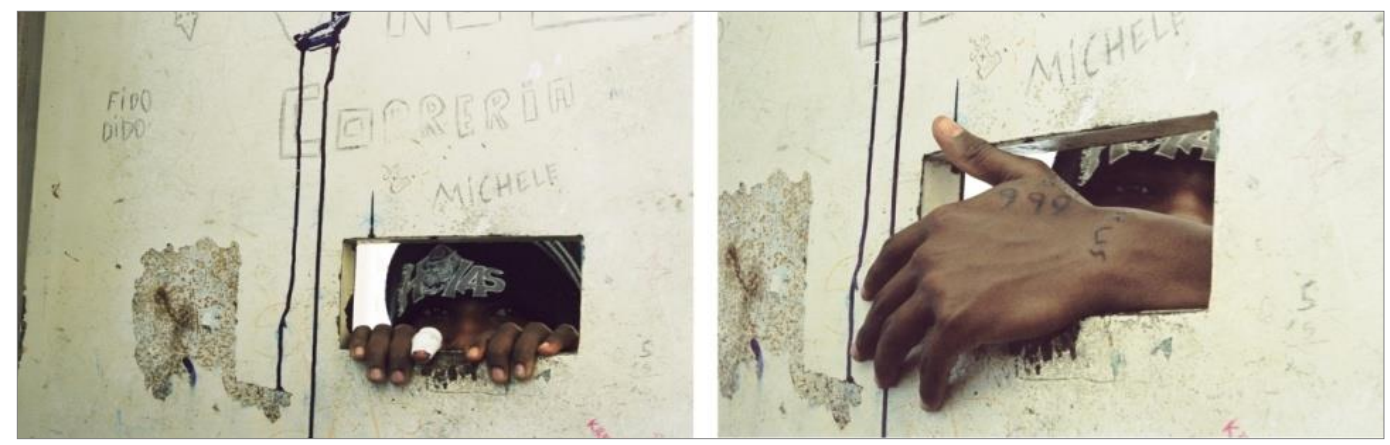

Fonte: ZIMERMANN, 2004.

Parte do trabalho teve início durante uma estada no Rio de Janeiro, quando realizava outra exposição intitulada Invólucro. Era maio de 2004, e, diante de uma sangrenta rebelião na Casa de Custódia de Benfica, as mídias jornalísticas abordavam o tema, espetacularizando a tragédia e reforçando o estigma da perversidade dos presos, responsabilizando-os unicamente.

Nesse sentido, Michel de Certeau propõe "táticas" desviacionistas, em que se utilize o sistema hegemônico com um fim diverso das "estratégias" tecnocráticas a que foi previsto. Para ele, o instante preciso de uma atuação "tática" pode ser oferecido pelas circunstâncias e o que distingue estas daquelas são os "tipos de operações", pois, no espaço em que as estratégias são capazes de produzir, mapear e impor, as "táticas" desviacionistas só podem utilizá-las, manipulando e alterando sua intenção, buscando também, a partir delas, reverter a captura e a subordinação às "estratégias" tecnocráticas. "As 'táticas' desviacionistas não obedecem à lei do lugar. Não se definem por este. Sob este ponto de vista, são tão localizáveis como as 'estratégias' tecnocráticas (e escriturísticas) que visam criar lugares segundo modelos abstratos" (CERTEAU, 1994. p. 92). 
Figura 2 - Instalação O lugar do outro

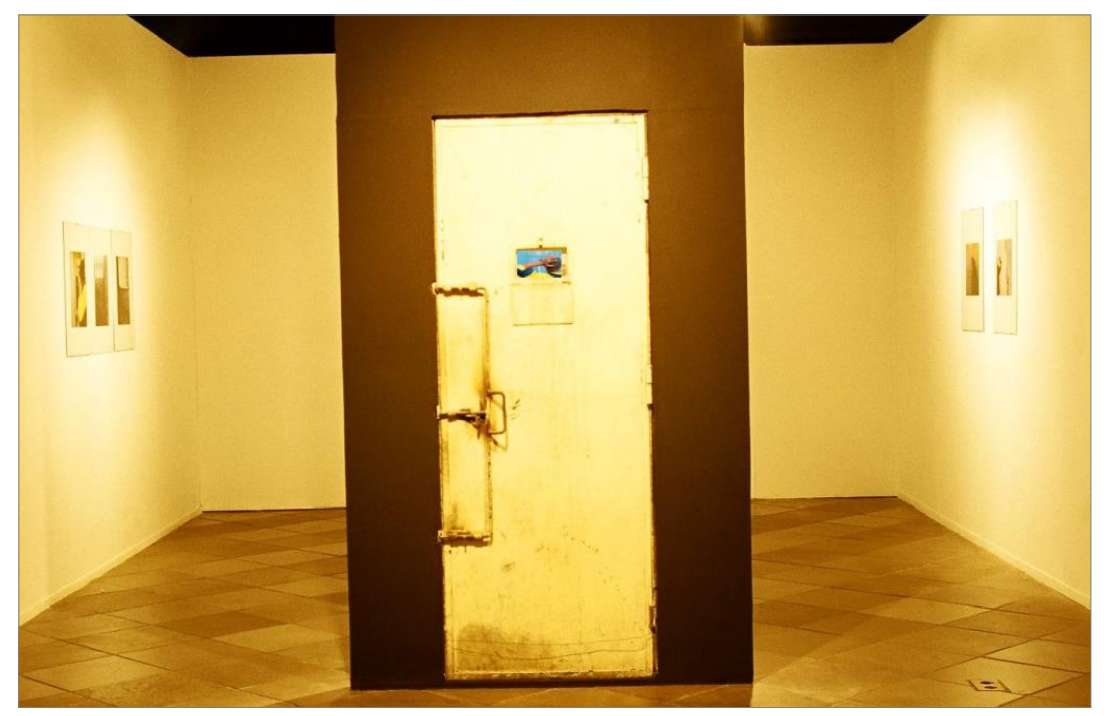

Fonte: ZIMERMANN, 2004.

Minha "tática" desviacionistas foi utilizar uma porta desativada, da própria instituição (figura 2), com sua carga energética e marcas do desejo de consumo, grafitadas pelos jovens infratores.

Imagens de um menino ali recluso e uma porta sem uso da própria instituição, representando o desconforto do claustro, foram os materiais dos quais se utilizou a artista Giovana Zimermann para denunciar os paradoxos do sistema prisional. (...) "O sistema prisional é o saldo que o País recebe pelas injustiças e pela desigualdade social, um círculo vicioso de violência e descaso, que se transforma a cada dia em um barril de pólvora, prestes a explodir", diz a artista. $(\ldots)^{1}$

Em outro ambiente fragmentei uma ampla matéria falando quanto custa para os bolsos do contribuinte a "escória da sociedade" (apenados), e coloquei os fragmentos dos papéis dobrados, acondicionados em dispositivos (assépticos de acrílico), diante de um nicho (uma janela, uma televisão, uma jaula). Nele fixei uma foto que fazia parte da matéria, e na qual via-se muitos jovens (todos negros e pardos) comprimidos contra uma grade de uma das celas da Casa de Custódia de Benfica (Figura 3).

A intenção era tirar o espectador da zona de conforto. Minha "tática" foi proporcionar uma imersão do espectador, convertido em "interator", já que estava em um espaço arquitetônico,

${ }^{1}$ SCHMIZ, Paulo Clovis. A arte comprometida. Revista Cartaz, 2004. p. 
interagindo com a obra. Como no biscoito da sorte "às avessas", o visitante era convidado a pensar somente sobre o fragmento que escolhera.

Figura 3 - Instalação O lugar do outro, 2004

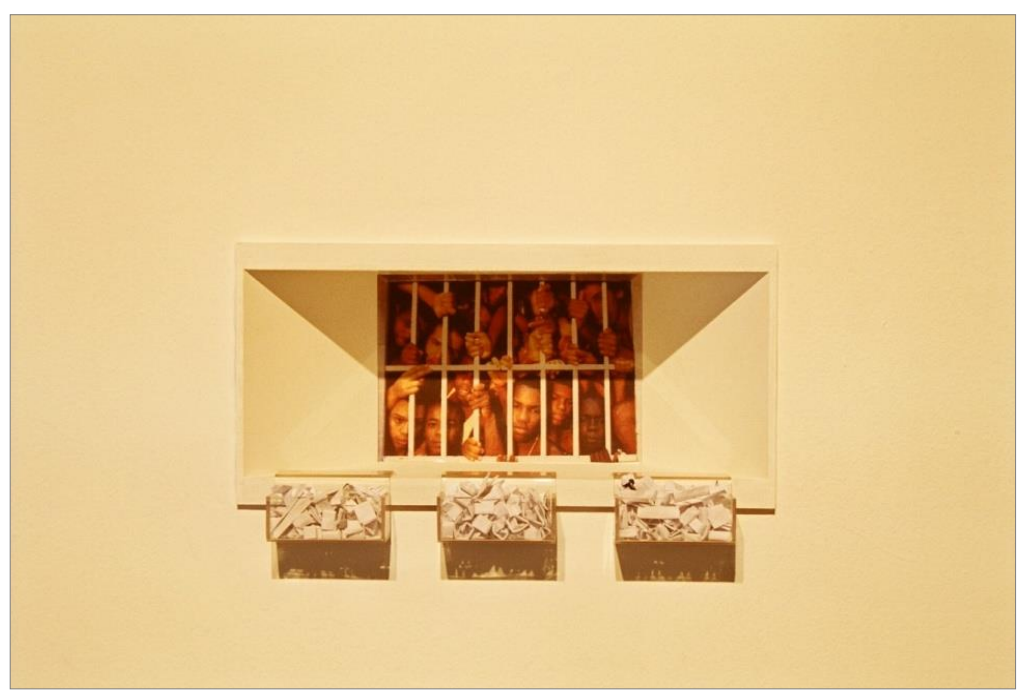

Fonte: ZIMERMANN, 2004.

Ao fazer uma aproximação da arquitetura com o cinema, Walter Benjamin fala da arquitetura como "protótipo de uma obra de arte", com a vantagem de uma recepção intuitiva, distraída e coletiva.

O filósofo, nesse sentido, estava atento à necessidade de novas formas de percepção, não apenas visual, através da contemplação. E, quando associa a arquitetura ao cinema, reivindica uma habilidade de recepção tátil, porque ocorre uma imersão física desse corpo ao lugar, que, no exemplo, era, então, O lugar do outro. A intenção era, assumidamente, "capturar" esse espectador (atraí-lo para contar algo), porém utilizando-se de outros meios (não esperando o recolhimento dele diante de uma obra), provocando-o. “Aliás, como para cada indivíduo existe a tentação de se furtar a tais tarefas, a arte conseguirá resolver as de maior peso e importância se conseguir mobilizar as massas. Concretiza-o no cinema atual” (BENJAMIN, 1992, p.110).

\section{Escreva a frase que te liberta, 2005}

Escreva a frase que te liberta, foi um projeto de Arte Relacional que aconteceu na continuação da mostra $O$ lugar do outro, e se estendeu pelo período de um ano. Nesse tempo, 
pude conviver com as "reeducandas" do Presídio Feminino, que faziam aulas de arte com a professora Liomar Arrouca. O trabalho começou com um caderno em branco. Nele eu me apresentava e convidava as mulheres que se sentissem motivadas a escrever suas ideias de liberdade. Minha intenção era questionar o sentido de liberdade dentro do ambiente de reclusão, mas acabou por agregar outra questão: por que aquelas mulheres se envolveriam?

Figura 4 - "Oficina de arte", 2005

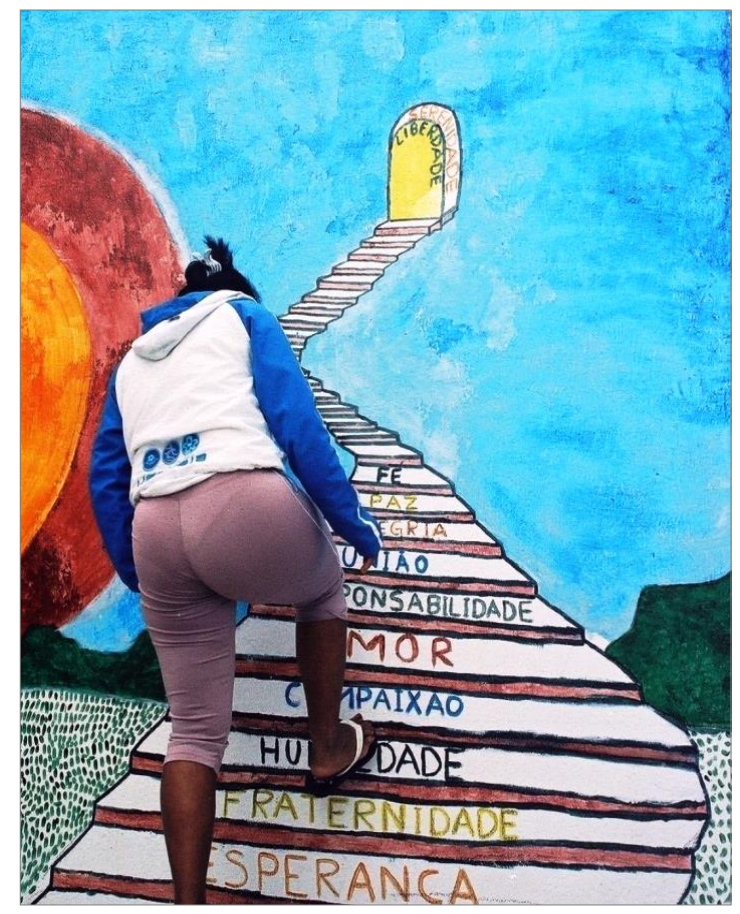

Fonte: ZIMERMANN, 2004.

Pelos depoimentos colhidos, tratou-se, também, de uma oportunidade de comunicação, uma oportunidade para desabafar, de ter alguma voz. O caderno ficou sob a responsabilidade de Carmem (Carmelita Julia), que o abriu com um desenho e um depoimento:

\section{Solidão!}

Escuridão!

Ao cair da noite vem a tranca, e com ela a sensação do que é de fato, a cadeia. Me dá uma depressão, não consigo dormir.

só penso em sair, a saudade aperta, mas só quem pode responder é a esperança da liberdade. Que demora, mas sei que chegará! ${ }^{2}$

\footnotetext{
${ }^{2}$ Depoimento de Carmelita Julia, reeducanda no Presídio Feminino de Florianópolis, para o projeto Escreva a frase que te liberta $2004-2005$.
} 
São histórias de perdas e mortes, de desagregação familiar, de submissão aos maridos e companheiros que, muitas vezes, as impulsionam para o mundo do crime, e contrastam com o desejo de retornar à vida, aos familiares, principalmente aos filhos.

Adélia Luzia conta que tem 23 anos e é natural de Florianópolis, mas vive em São Pedro de Alcântara desde que nasceu. Está presa há sete meses com base no Artigo $157^{3}$. Conta que é mãe de duas lindas meninas gêmeas, de 5 anos, que se chamam Urainara e Urainá.

Relata Adélia,

Nestes sete meses que estou aqui, deu para refletir tudo o que aconteceu na minha vida e me arrependo de tudo o que fiz. Meus pensamentos. Depois de algum tempo você aprendeu a diferenciar a sutil diferença entre dar a mão e acorrentar a alma. E você aprende que amar não significa segurança começa a aprender que beijos não são contratos, e começa aceitar suas derrotas. ${ }^{4}$

Figura 5 - "Oficina de arte", 2005

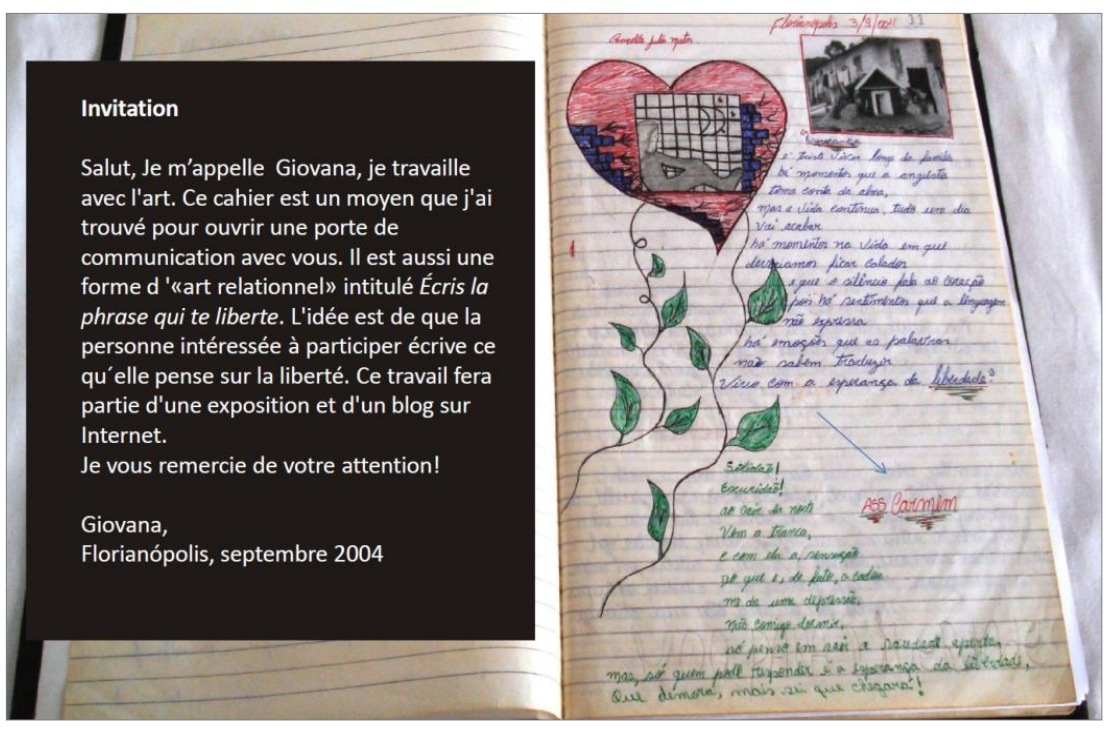

Fonte: ZIMERMANN, 2004.

\footnotetext{
${ }^{3}$ Artigo 157 do Decreto Lei no 2.848 , de 07 de dezembro de 1940.

Art. 157 - Subtrair coisa móvel alheia, para si ou para outrem, mediante grave ameaça ou violência à pessoa, ou depois de havê-la, por qualquer meio, reduzido à impossibilidade de resistência:

Pena - reclusão, de quatro a dez anos, e multa. < http://www.jusbrasil.com.br/jurisprudencia/ >

${ }^{4}$ Depoimento de Adélia Luzia, reeducanda no Presídio Feminino de Florianópolis para o projeto "Escreva a frase que te liberta" $2004-2005$.
} 
Cientes de que todas as suas cartas e mensagens são monitoradas, e evidentemente, de que o caderno também seria antes de voltar para minhas mãos, muitas mensagens foram elaboradas, evidenciando um apelo de arrependimento: "Todos nós precisamos dessa tal liberdade, mas também temos que pagar pelos nossos erros". (Figura 5).

Com o tempo, fui percebendo que o corpo era o suporte intransponível da expressão de liberdade, ou das manifestações de fé, esperança e amor aos que deixaram do lado de fora. Passei a fotografar as tatuagens, dando preferência para aquelas realizadas dentro do presídio: "Meu amor por eles é fiel S, L, A", "Só Deus sabe a minha hora!", "Vida Loka!", "Eliane, amor verdadeiro, Amor Eterno"5.

Um dia, fui abordada por uma mulher: "Você quer fotografar minha tatuagem"? Mostrou, em sua perna, a imagem de um cachorro bravo com um pedaço de pau na mão, e falou: "Meu exmarido sempre me cobrava que tatuasse seu nome no meu corpo, um dia eu tatuei isso e falei para ele, esse é você!" E complementou: "Ele é muito mau!".

No dia 24 de novembro de 2005, realizei a exposição Escreva a frase que te liberta no Museu da Imagem e do Som, em Florianópolis/ SC, e dentro do presídio feminino, com fotos que, depois, foram doadas para as pessoas fotografadas. Junto com a exposição, foi realizado um fórum intitulado Sobreliberdade, com o intuito de debater sobre a necessidade de maior investimento na profissionalização das mulheres que estão no Sistema Prisional, visto que correm o risco de cumprir suas penas e, sem qualificação profissional, reincidirem, mais facilmente, no crime. No fórum foi exibido, em pré-estreia, o filme $O$ cárcere e a Rua, 2004, da diretora Liliana Sulzbach, que também exibiu seu documentário no Presídio Feminino, por nossa solicitação.

${ }^{5}$ Depoimento anônimos das reeducanda no Presídio Feminino de Florianópolis para o projeto "Escreva a frase que te liberta" $2004-2005$. 
Figura 6 - Na Pele, 2012

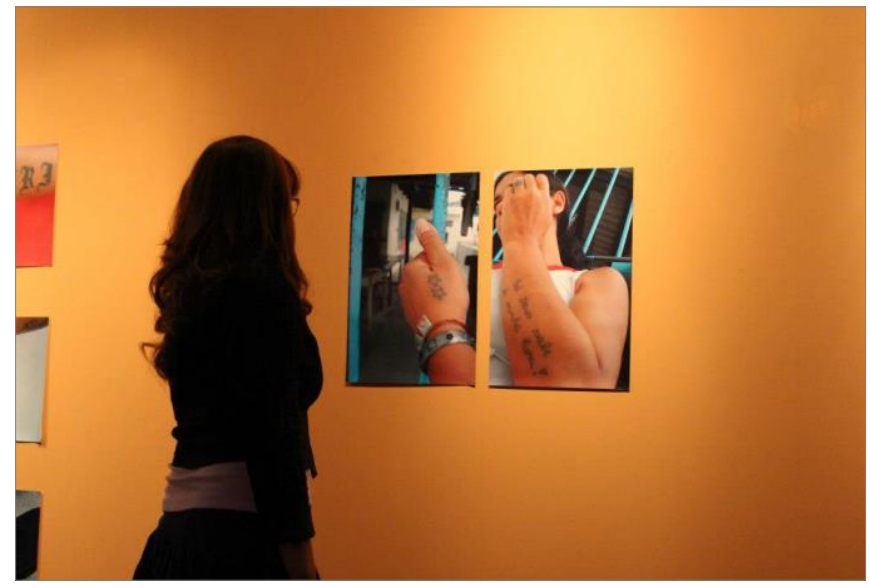

Foto: Ana Ligia Becker, 2012

Em 2012, a exposição Escreva a frase que te liberta foi apresentada na Université Paris Diderot, a convite da Associação Anthropologie et Photographie ${ }^{6}$, retornando para o Museu da Imagem e do Som com o título Na Pele. 2012. Tratou-se de uma retrospectiva de trabalhos desenvolvidos ao longo de 8 anos, que traduzem minhas impressões no campo social. Fotografias da série $O$ lugar do outro, fotografias da mostra Escreva a frase que te liberta e fotografias do filme Da Janela, com a exibição do mesmo.

Desde o princípio estava previsto um debate em torno dessa produção, e ele aconteceu no dia 22/11/2012 - 19:00h, contando com um público muito mais direcionado ao assunto (violência de gênero e sistema prisional), resultando em um processo de rede e, felizmente, atingindo o propósito a que o trabalho se propunha.

Apresentei o projeto, passei a palavra para cada um dos participantes, que puderam falar sobre sua atuação no que se refere ao assunto Sistema Prisional. Participaram do debate: o Dr Enio Gentil Vieira Jr., Defensor Público da Infância e Juventude Tribunal de Justiça de Santa Catarina (TJSC); Lílian Domingues, Coord. Estadual da Infância e da Juventude (TJSC/CEIJ); a psicóloga Maíra Marchi, da Secretaria da Segurança Pública/Delegacia da Mulher; Heloisa Petry, Psicologia da Justiça Restaurativa; Rosana Volkmann Paschoal, da Escola Supletiva da Penitenciária Florianópolis; Beatris Clair Andrade, da Secretaria da Educação (SED/SC), Cristiane Pedrini Ugolini administradora do Museu da Imagem e do Som (MIS) e público em geral.

${ }^{6} \mathrm{https}: / /$ anthropophoto.wordpress.com/agenda/ 
No dia 30/11/2012, o público foi um grupo de reeducandos da Penitenciária de Florianópolis, que participava do Projeto CONSTRUINDO, um projeto de arte educação desenvolvido em parceria com o -Museu Histórico de Santa Catarina (MHSC) / Palácio Cruz e Sousa e Museu da Imagem e do Som de Santa Catarina (MIS/SC). Oferecia-se, assim, uma grande oportunidade de ouvir a voz de dentro do Sistema Prisional, dando oportunidade de convívio social e cultural, valorizando a autoestima dessas pessoas que se sentem à margem.

A conversa com os reeducandos girou em torno de perspectivas; falou-se de sonhos, de projetos de vida, de formas de conquistar espaço no mercado de trabalho; e, principalmente, destacou-se a oportunidade que eles estavam tendo de uma nova chance, para uma liberdade mais digna.

Foi importante receber o Projeto CONSTRUINDO dentro da mostra Na Pele, e de contar com os depoimentos dos reeducandos no caderno de depoimentos do Projeto Escreva a frase que te liberta, iniciado em 2004. Sem dúvida é um avanço, pois, em 2005, a Carmem, que se ocupou em colher os depoimentos no caderno de memórias das mulheres do Presídio Feminino, pode participar da exposição que aconteceu dentro do Museu, representando as outras mulheres que participaram do projeto, somente mediante uma liminar concedida pela justiça. Depois da experiência, ela falou que nunca iria esquecer o "cheiro do museu".

Minha intenção era captar as mensagens escritas dentro do presídio, a identidade literal não foi revelada, porém a identidade adotada, em forma de texto gravado na própria pele, ganhou ênfase, pois a escolha do suporte corpo revela autonomia intransponível. No livro de depoimentos, as mulheres revelam diversos casos de violência, opressão, conteúdo que me afetou, e aumentou minha potência para prosseguir na apresentação desse tema tão delicado, através da sensibilidade da arte. 


\section{DA JANELA, 2009}

Figura 7 - Da Janela, 2009

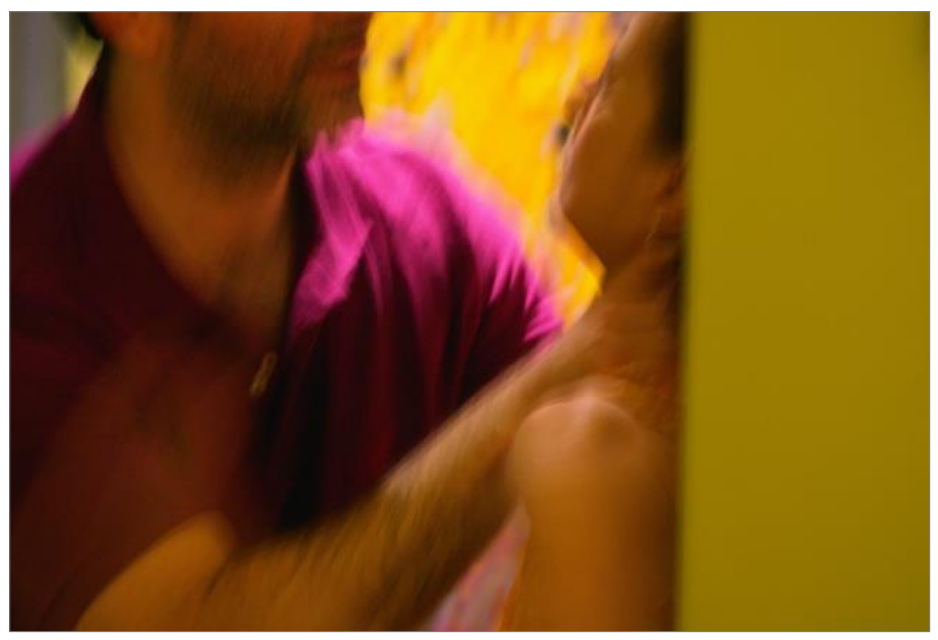

Foto: Anelise Borges, 2008.

Em 2002, quando dava carona para uma jovem mulher, no espaço de tempo de 4 horas, ela me relatou sobre um "trauma” (um estupro sofrido em São José dos Pinhais - PR). Eu não tinha para onde fugir, estava dirigindo, e sua trágica história era lançada na minha retina através do para-brisa do carro. Chegando ao destino, me despedi da jovem mulher, mas fui afetada pela sua história. Escrevi, acho que para me livrar! "Eu escrevo como se fosse para salvar a vida de alguém. Provavelmente a minha própria vida", parafraseando Clarice Lispector.

Ao passar do tempo, em favor da poética, o roteiro foi adquirindo um corpo ficcional, especialmente por desejar construir uma estética feminina e, até certo ponto, delicada apesar da densidade do assunto abordado. Um dia presenciei, no trânsito, a cem metros da minha casa, uma mulher sendo empurrada para dentro de um carro (marido inconformado com separação tenta levar mulher a força de volta para casa). Entendi que meu roteiro deveria abordar a violência doméstica, mas velada, entre quatro paredes. Recebi o prêmio para realizar o filme em 2005 (um ano antes de a Lei Maria da Penha entrar em vigor) porém a verba demorou cerca de três anos para ser depositada, tempo suficiente para que eu pudesse experimentar a violência conjugal (psicológica), uma das mais injustas, pois não deixa marcas visíveis.

A psicóloga Mariana Lange, que cedeu seu consultório para locação do filme, interage com meu depoimento em blog, refletindo sobre as interrogações em torno da relação existe entre a vítima, o belo e o sofrimento. 
Existe tudo isso sem a lei? Existe vítima sem carrasco? Existe prazer e gozo no sofrimento? E no fazer sofrer? Mas, afinal, o que é o sofrimento?

Parece que a escrita tem uma relação privilegiada com a fantasia, que é nada menos que um dos pilares que sustentam as questões acima. Além disso, a ética se coloca também como conceito fundamental nesta discussão. Sade coloca que a escrita pode fazer ver o que do homem existe em potência, o que ele pode vir a ser caso se deixe mover pelas paixões (no sentido de Pathos, paixão/sofrimento). Não foi isso que fez Antígona?

Sade fala de vítimas ornadas de belezas - e Lacan também. Freud falava em miséria neurótica. Sade também? Qual a relação entre a miséria, o sofrimento e o belo? Certamente não responderei agora. Mais Kant, mais Sade, mais Direito, mais Literatura, e mais tinta na pena...

Não sei exatamente porque lembrei dele hoje, acho que tem a ver com o que você traz sobre o sofrimento psíquico que não deixa marcas visíveis - mas certamente deixa marcas cuja cicatrização pode levar mais tempo que uma chaga aberta. Neste texto quis juntar "neurótico" com "ética", ficou "neurética", uma espécie de ética maluca que nos move e nos deixa, inclusive, fazer parte de abusos que poderiam ser evitados... Enfim, mistérios da alma... (LANGE, 2008).

No filme, o espectador é conduzido por um túnel, com a intenção de criar um canal de tensão em torno do assunto e Inicia-se, de fato, com um fragmento do filme Irreversível, 2002, do diretor Gaspar Noé, que está sendo assistido pela personagem, que é uma fotógrafa. Trata-se de um filme ícone na abordagem sobre a violência contra a mulher. Por ser um curta-metragem, esta foi uma maneira encontrada para introduzir o espectador na densidade do assunto, bem como o foco de interesse da fotógrafa.

O trecho que elegi, em realidade, retoma seus filmes anteriores. A fala é do açougueiro (Philippe Nahon), do curta-metragem Carne, que também atua em seu primeiro longa Contra Todos [Seul contre tous], que, já no presídio, fala para o companheiro de cela: "Fui preso porque transei com minha filha", e o outro responde: "Ah! a síndrome ocidental" (Irreversível, 2002). Uma maneira de abordar a violência sexual dentro de casa.

Da janela leva o espectador a transitar por esse universo emaranhado de fragilidade e brutalidade, através dos seus olhos e do seu imaginário. Há uma relação entre as janelas da casa ou do carro da protagonista, que funcionam como um "olho câmera", pois é através delas que estará recortando tudo o que vê. Cada vez que um personagem é visto por ela, ele constitui vida na trama, e sua história se torna independente do seu olhar.

O filme não trata só de vilões e de vítimas, mas de pessoas psicologicamente desestruturadas, profissionais despreparados para atender os casos de violência de gênero. $\mathrm{O}$ policial que recebeu a jovem do depoimento perguntou-lhe que tipo de roupa estava vestindo, 
como se esse quesito autorizasse o crime. Senti necessidade de incluir uma cena para pontuar "o direito à sensualidade". Nela, todas as mulheres vestem vestidos vermelho.

Figura 8 - Da Janela, 2009

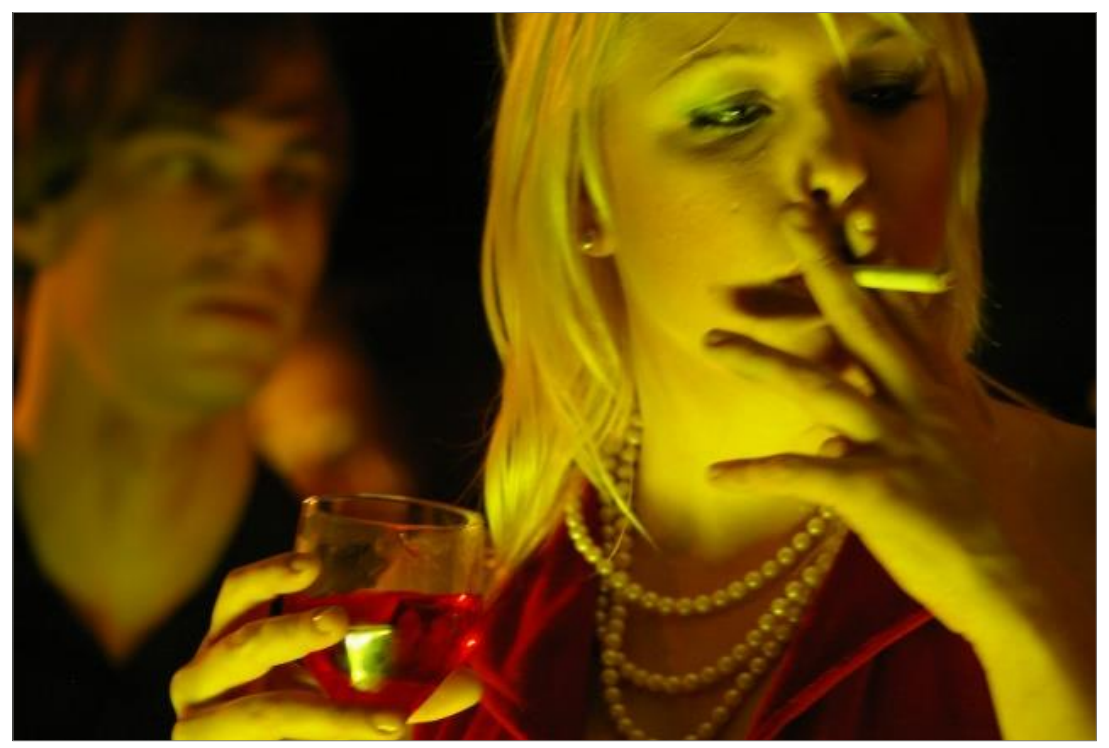

Foto: Anelise Borges, 2008

Apesar de falar de violência, o roteiro é poético, não abusando do apelo da "violência pela violência", mas explorando da semióticas para falar do assunto e também do descaso. Ocorre, um estupro em um beco, em pleno centro da cidade, no entanto, ninguém vai à janela, os carros passam, todos se omitem, a vida continua.

Há uma angústia e uma dúvida quanto à possibilidade de uma obra denúncia, do cunho do Da Janela ter a eficiência em seu propósito, e não somente mobilizar a violência como tema polêmico. Mas as respostas, confirmando a relevância do assunto, sempre chegavam a tempo. No dia mais delicado, o dia da gravação do estupro, surge o depoimento de uma assistente social, espectadora do páthos trágico de uma mulher mutilada pelo seu "marido", como no caso de Maria da Penha Maia Fernandes, cujo nome foi inspirador da Lei n ${ }^{\circ}$ 11.340.

Da Janela foi filmado em meados de outubro de 2008; o Brasil assistia pelos noticiários ao "Caso Eloá" - A jovem Eloá Cristina Pimentel, de 15 anos, estava sendo mantida em cativeiro pelo ex-namorado Lindemberg Fernandes, de 22 anos, que não se conformava com o fim do relacionamento.

Da janela, Eloá implorava pela própria vida, que lhe foi ceifada. 
Figura 9 - Da Janela, 2009

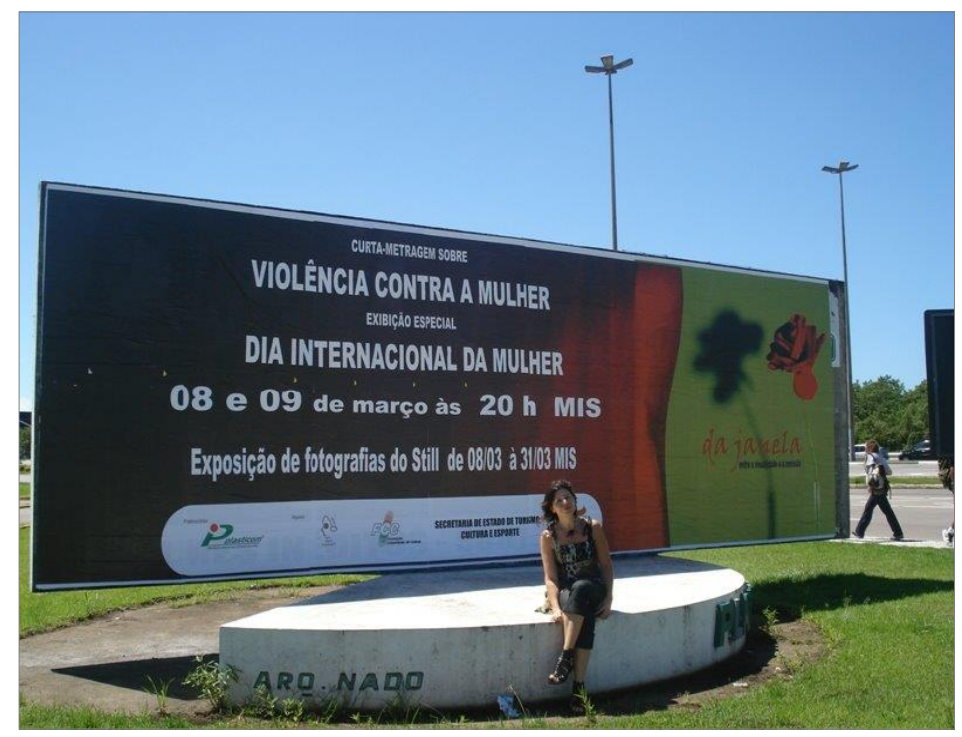

Fonte: ZIMERMANN, 2009.

Da Janela foi exibido em diversos festivais e eventos de gênero, em muitos deles com debates, envolvendo: artistas, médicos, enfermeiros, psicólogos e psicanalistas. Em grande parte das exibições em que pude acompanhar o filme, depois alguma vítima me procurava para dar seu depoimento. A última exibição que acompanhei o filme foi em Faro, no Algarve, depois da exibição recebi um papel e nele estava escrito: "Fui estuprada duas vezes, quer me conhecer?” A última exibição foi em uma mostra de curta-metragens, no evento: "Genre et images dans le monde ibéro-latino-américain"7 no Laboratório Crimic, na Université Paris Sorbonne, no dia 10 de outubro de 2015.

Todos os debates me motivaram a escrever outros dois curtas com o intuito de fechar o ciclo aberto pelo Da Janela. Do ponto de vista das cores, trata-se de uma citação à trilogia Trois Couleurs: Bleu/Blanc/Rouge, de Krzysztof Kieślowski (1993-1994). No Da Janela, o vermelho remete à sensualidade e à violência; em $\operatorname{branCURA,~o~branco~remete~à~limpeza~obsessiva,~mas~}$ também à lacuna deixada pelo trauma; e, no último, A Cor da Liberdade, será a vez do azul, como transcendência.

Da Janela. Direção: Giovana Zimermann e Sebastião Braga, Brasil, cor, 15 min, 2009.

\footnotetext{
${ }^{7}$ http://www.crimic.paris-sorbonne.fr/manifestations/genre-et-images-dans-le-monde-ibero-latino-americain/
} 


\section{Sinopse}

Fotógrafa pesquisa sobre a violência contra a mulher. Através da janela de sua casa ou do carro, seu "olho câmera" registra tudo. Os planos se cruzam, criando um universo onírico, composto de cenas de violência simultâneas a cenas de uma festa, propiciando a reflexão de que, ao mesmo tempo em que o espectador assiste ao filme, muitas mulheres anônimas são expostas à violência. ${ }^{8}$

FICHA TÉCNICA

DIREÇÃO: Giovana Zimermann E Sebastião Braga,

ROTEIRO E STORYBOARD: Giovana Zimermann,

DIREÇÃO DE PRODUÇÃO: Sofia Mafalda E Fabiola Becker

EDIÇẪO: Tiago Santos,

ELENCO: Elianne Carpes, Giovana Zimermann, Luiz Claudio Leite,

Marcos José Santin, Marta Cesar E Noara Quintana.

PREPARADORA DE ELENCO: Elianne Carpes,

DIREÇÃO DE ARTE: Lina Lavoratti,

DIREÇÃO DE FOTOGRAFIA: Martin Carvalho,

ELETRECISTA: Dill,

TRILHA SONORA: CURANDERA: COMPOSIÇÃO E VOCAL: Guilherme Zimermann

Kummer

ARRANJO MUSICAL: Frederico Teixeira e Du Gomide.

ASSISTENTEDE DE ARTE: Stella Bloss, Figurino: Moara Costenaro

ASSISTENTES: Silvio César e Lua

MAQUINISTA: Ricardo Xará

SOM DIRETO: Paraíba

MAKING OFF: João Abreu Dias

STILL: Anelise Borges.

${ }^{8}$ ZIMERMANN, Giovana. Disponível em:<https://www.youtube.com/watch?v=lg8uTMBSzYg Acesso em: 25 de fevereiro de 2016. 


\section{4. branCURA}

Figura 10 - branCURA, 2016

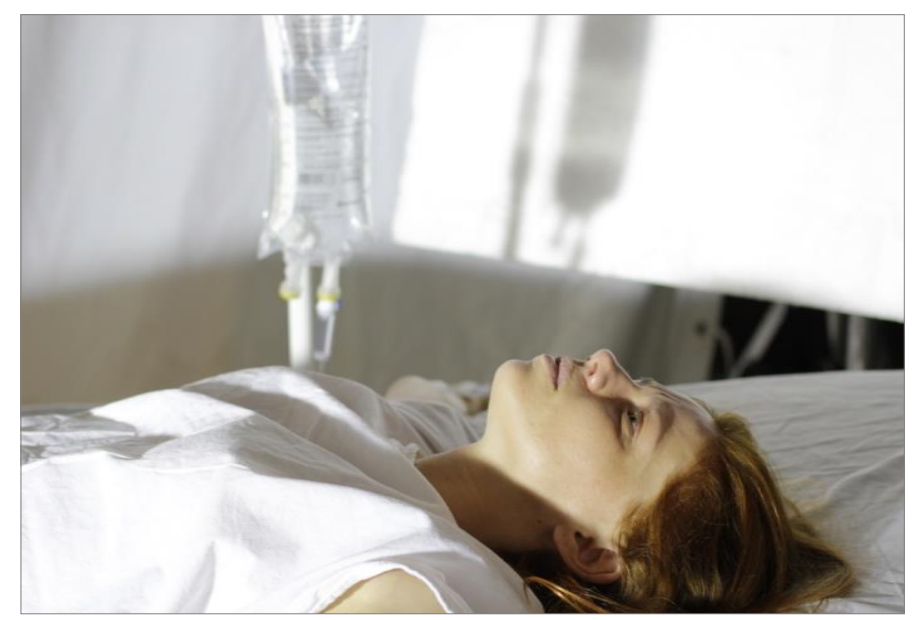

Foto: Beta Iribarrem, 2014

O título é motivado pela ideia lacaniana de que a arte se constrói em torno do vazio (branco), e o artista tem, na criatividade, uma forma de restabelecer seus laços com o mundo (CURA). A arte começa onde o que não pode ser dito, pode ser mostrado e, até mesmo exibido. Então, o suspeito é olhado pela obra de arte, provocando um efeito perturbador. Mais tarde, encontrei o conceito de "brancura", na contemporaneidade: "enquanto os pacientes de Alzheimer são corroídos por 'brancos', os adolescentes desenvolvem 'técnicas de brancura' para se livrar de si mesmo", segundo David Le Breton.

A construção da dramaturgia está sedimentada na arte e na psicanálise, de modo que os aspectos subjetivos, como devaneios, têm primazia na história de Aimèe (Angélica Mahfuz). O espectador é levado a transitar pelo inconsciente de uma jovem que sofreu violência sexual, mas que, em resposta ao trauma, desenvolve uma psicopatologia. Esse sintoma de obsessão com a limpeza do próprio corpo em psiquiatria, é designado com a sigla TOC (Transtorno Obsessivo Compulsivo) e, em psicanálise, aponta para uma "neurose obsessiva". Aimèe desenvolveu "técnicas de brancura" para se livrar de si mesma, refugiando-se no inconsciente, escapando da vida real e mergulhando na arte.

São diversas as referências das artes, algumas intencionais (citações) e outras que foram surgindo mesmo depois do roteiro escrito. A cena em que Aimèe está diante do armário, por 
exemplo, pensei inicialmente em uma pessoa com mania de organização e que, ao contemplar o próprio armário, observava-o como quem observasse um quadro. Depois, decidi que ele seria a reprodução de um quadro de Mondrian: Composição com vermelho, amarelo e azul (Figura 11). A posição de Aimèe diante do quadro é uma referência direta à fotografia Le Violon d'Ingres, de Man Ray, e Henry Forde Hospital - La cama volando, de Frida Kahlo que me inspirou para a cena do hospital.

Figura 11 - branCURA, 2016

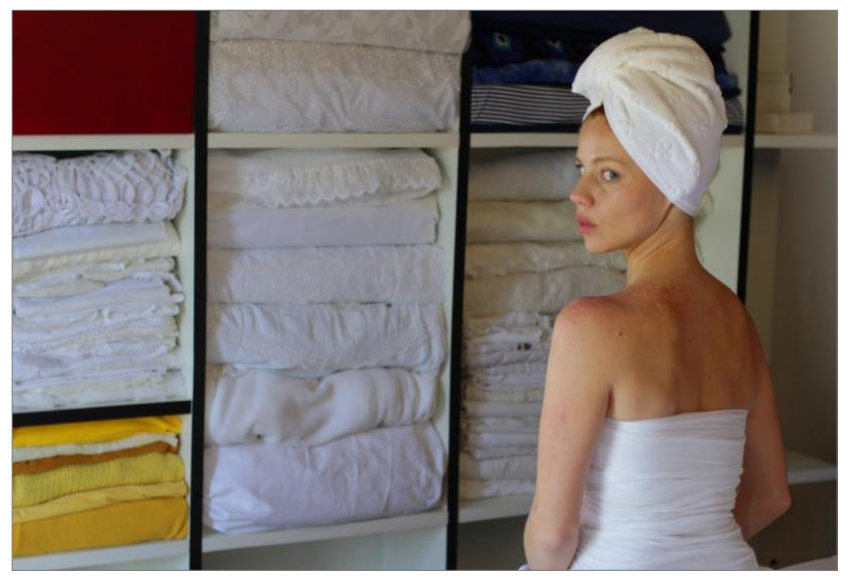

Foto: Beta Iribarrem, 2014.

A principal locação foi em um ateliê de gravura. A escolha da gravura em metal foi para traduzir, de forma mais visceral, a fúria da personagem, a construção do próprio objeto (cinto de castidade), que também remete à fusão das linguagens escultura/gravura.

Aimèe é uma personagem complexa, solitária, que está atormentada com fantasmas do passado, traumas de infância e adolescência, relacionados à violência de gênero (viu sua mãe ser assassinada e, na adolescência, sofreu violência sexual, seguida de gravidez, e, sem a aprovação legal, ela própria faz o aborto, o que lhe agrava o caso de culpa). Em crise, ela pensa em tirar a própria vida, mas é interrompida por Louis, um jovem que praticava parkour perto da ponte Hercílio Luz, onde o romantismo é marcado.

A dimensão da paisagem vai se agigantando enquanto a personagem vai se tornando ínfima. A luz e a cor da imensidão da natureza entram em contraste com a protagonista, praticamente, apagada diante do mar e da montanha. A constatação de que nada podia ser maior do que o divino aparece nas pinturas românticas, despertando o sentimento de insignificância nos 
indivíduos. O sentimento obscuro de Aimèe, suas ideias confusas podem ser avaliadas pelo "sublime" do romantismo de Edmund Burke, um sentimento de estar diante de um perigo, um sentimento de dor de estar no limiar da morte. Sem o Romantismo, o Simbolismo não existiria, mas ele aprofunda caminhos mais ousados e irracionais, um mergulho nos recantos mais ocultos do inconsciente da personagem.

Segundo Freud, a neurose obsessiva estaria ligada à vida sexual precoce, tendo como característica fundamental seu vínculo estrutural com o sentimento de culpa (KAUFMANN, 1996). Mas de onde adviria essa culpa tão presente, e, ao mesmo tempo, tão escondida pelo neurótico obsessivo? As pistas ficam por conta do poema Femmes damnées, de Baudelaire, que aborda um tema provocador, uma evocação aberta sobre a homossexualidade feminina. O poema é composto de antíteses/ ambivalências: douces langueurs et des frissons amers [Têm doce languidez e calafrios amargos], Vont épelant l'amour des craintives enfances [Vão soletrando o amor da tímida infância], L'écume du plaisir aux larmes des tourments [ A espuma do prazer com as lágrimas dos tormentos], emoções contrárias ou ambivalentes... Aimèe encontra na avó um aconchego, um ninho que lhe dá segurança. Mas ela precisa fazer a passagem (a jornada da heroína) para transcender ao trauma. Parece que a figura quase feminina de Louis lhe inspira confiança no sexo oposto novamente.

O poema Região Azul..., de Cruz e Sousa, indica um processo de cura de Aimèe. "E o azul, o azul virginal onde as águias e os astros gozam, tornou-se o azul espiritualizado, a quint'essência do azul que os estrelejamentos do Sonho coroam"... é como se a personagem, que é artista, falasse de sua busca pela liberdade, pela "harmonia azul, que é [...] ao mesmo tempo cor e ao mesmo tempo som..."

branCURA. Direção: Giovana Zimermann, Brasil, cor, 15 min, 2016.

\section{Sinopse}

Após violências sofridas na infância e na adolescência, Aimèe (Angélica Mahfuz), embora bonita, toma cuidados para não ser percebida, sublima a sensualidade, entendendo-a como uma ameaça. Ambígua, pensa em tirar a própria vida, mas é interrompida por Louis (Johny Bruckhoff). Usa a arte na luta contra uma neurose obsessiva. Vê em seu processo criativo uma possibilidade de suprir a lacuna deixada pelo trauma. ${ }^{9}$

\footnotetext{
${ }^{9}$ Disponível em:< https://www.facebook.com/filmebranCURA/> Acesso em: 25 de fevereiro de 2016.
} 


\section{FICHA TÉCNICA}

DIREÇÃO

Roteiro e direção: Giovana Zimermann

$1^{\circ}$ Ass. de Direção: Thais Aguiar

$2^{\circ}$ Ass. De Direção: Thais Alemany

ELENCO

Prod. Elenco: Elianne Carpes

Preparação de elenco: Elianne Carpes

Aimée: Angélica Mahfuz

Louis: Johny Fabricio Bruckhoff

Avó Julieta: Elianne Carpes

FOTOGRAFIA

Diretor de Fotografia: Roberto Santos (Tuta)

$1^{\circ}$ Assis. de Câmera: Cristina Kreuger (Kike)

$2^{\circ}$ Assis. de Câmera: Danilo Rossi

Câmera subjetiva: Johny Fabricio Bruckhoff

Making off: Leandro Elsner

ARTE

Direção de Arte: Giovana Zimermann e Policarpo

Graciano Pinto

Assistente de arte: Maria Fernanda Bin

Beleza: Kellen Kristine Silveira

Figurino : Singra Zimermann

ANIMAÇÃO
Desenho com fios de cabelo: Giovana Zimermann Animação stop motion: Camila Kauling Rumpf Pós produção: Moacir Barros

PRODUÇ̃̃̃O

Direção de Produção: Marina Teixeira

Secretária Produção: Roberta Iribarrem

Platô: Leandro Dias

FINALIZAÇAO

Editor: Alan Porciuncula

Color Grading: Alan Porciuncula

$1^{\circ}$ corte: Rodrigo Goes

DESIGNER DE SOM

Daniel Téo

Marcelo Téo

TRILHA

Kamma No - Terra Sonora

Operador Som: Paulo Achut Cicero

Voz off : Angélica Mahfuz

Voz off francês: Thais Alemany

ELÉTRICA

Chefe de Elétrica: Hercules Jerônimo Jesus

$1^{\circ}$ Assis. De Elétrica: Carlos Lenine

MAQUINÁRIA

Chefe de Maquinaria: Claudio Reginatto

$1^{\circ}$ Assis. Maquinaria: Lenon Oliveira 


\section{CONSIDERAÇÕES FINAIS}

O que nos move no mundo envolve compromissos com temas que sempre nos foram caros. No fundo, é sempre uma preocupação existencial. Encontramo-nos, inicialmente, com nós mesmos; esse é o limiar de nossa experiência afetiva. Não é incoerente dizer que meu trabalho está gestado em uma questão existencial e ligada ao feminino, mesmo sendo uma visão pessoal de uma realidade aparentemente externa. Então me pergunto: Por que me afeta? Por que reajo e gasto energia questionando as violências do mundo, em especial as que são cometidas contra as mulheres? Qual é a ferida que pretendo curar com meus empreendimentos artísticos? O enfoque psicanalítico da trilogia dá pistas dessa busca venturosa, a qual está relacionada com os três tempos mencionados por Jacques Lacan: instante de ver (Da Janela); tempo para compreender (branCURA); e momento de concluir (A Cor da Liberdade).

Segundo Spinosa, experimentar os afetos é, primeiramente, nos experimentar, ou seja, é desta maneira que formamos um primeiro conhecimento de nossa constituição. Torná-los visíveis, compartilhar esse exercício está ligado à capacidade de uma afecção que nos leva para uma potência maior de ser e agir no mundo. "[...] permanecemos ainda separados de nossa potência de agir, não a possuímos formalmente, [...] 'aproximamo-nos' do ponto de conversão, do ponto de transmutação que nos tornará senhores dela, e, por isso, dignos de ação, de alegrias ativas" (DELEUZE, 2009, p.34).

"A arte começa onde o que não pode ser dito, pode ser mostrado e, até mesmo exibido." A capacidade de fazer uso da arte como "tática desviacionista", como nos sugere Certeau, é, em certo sentido, sentir-se capaz de reagir diante dos afetos. É ser sábio, passar da paixão à ação, e, dessa forma, alcançar a "cura", a "transcendência", a liberdade. 


\section{REFERÊNCIAS}

BENJAMIN, Walter. Sobre Arte, Técnica, Linguagem e Política.Trad. Maria Luz Moita. Lisboa: Relógio D’Água,1992.

BRANCURA. Direção: Giovana Zimermann, Brasil, cor, 15 min, 2016.

DA JANELA. Direção: Giovana Zimermann, Brasil, cor, 15 min, 2009.

CERTEAU, Michel. A invenção do cotidiano: arte de fazer. Petrópolis: Vozes, 1994.

DELEUZE, Gilles. Cursos sobre Spinoza (Vincennes, 1978-1981). Tradução E. A. R. Fragoso, F. E. B. Castro, H. R. Cardoso e J. A. Aquino. Fortaleza: EdUECE, 2009.

FOUCAULT, Michel. História da loucura na idade clássica. São Paulo: Perspectiva, 2004.

FREUD, S. Notas sobre um caso de neurose obsessiva. Imago: Rio de Janeiro, 1909.

KAUFMANN, P. Dicionário enciclopédico de psicanálise: o legado de Freud e Lacan. Rio de Janeiro: J. Zahar, 1996.

LANGUE, Mariana. NEURÉTICA (Kant com Sade). Filme da Janela. Disponível em:<http://filmedajanela.blogspot.com.br/search?updated-min=2008-01-01T00:00:0008:00\&updated-max=2009-01-01T00:00:00-08:00\&max-results=16> Acesso em: 26 de janeiro de 2016.

SCHMIZ, Paulo Clovis. A arte comprometida. Revista Cartaz, 2004.

ZIMERMANN, Giovana. Filme da Janela. Disponível em:< http://filmedajanela.blogspot.com.br/search?updated-min=2008-01-01T00:00:0008:00\&updated-max=2009-01-01T00:00:00-08:00\&max-results=16>. Acesso em: 26 de janeiro de 2016.

Giovana. Youtube. Disponível em:<

https://www.youtube.com/watch?v=lg8uTMBSzYg>. Acesso em: 25 de fevereiro de 2016.

Giovana. Facebook. Disponível em:<

https://www.facebook.com/filmebranCURA/>. Acesso em: 25 de fevereiro de 2016. 